The Israeli Journal of Aquaculture - Bamidgeh, IIC:63.2011.635, 6 pages

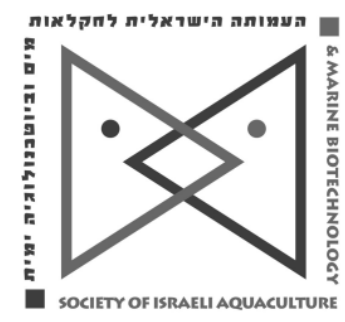

The IJA appears exclusively as a peer-reviewed on-line open access journal at http://www.siamb.org.il

Sale of IJA papers is strictly forbidden.

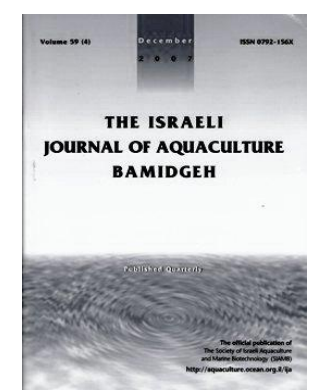

\title{
Effect of Glycerol on Fertility of Cryopreserved Grass Carp (Ctenopharyngodon idella) Sperm
}

\section{Yusuf Bozkurt ${ }^{1} *$, İlker Yavaş ${ }^{2}$, Fatih Öğretmen ${ }^{3}$, Buğra Sivaslıgil $^{2}$, Fikret Karaca ${ }^{2}$}

${ }^{1}$ Department of Aquaculture, Faculty of Fisheries, Mustafa Kemal University, Hatay, Turkey

2 Department of Animal Reproduction and Artificial Insemination, Faculty of Veterinary Medicine, Mustafa Kemal University, Hatay, Turkey

${ }^{3}$ State Hydraulic Works (SHW) Fish Production Station, Adana, Turkey

(Received 3.9.10, Accepted 9.11.10)

Key words: grass carp, Ctenopharyngodon idella, cryopreservation, glycerol, extender, semen, fertilization

\begin{abstract}
This research investigated the effect of adding glycerol to different ionic extenders on motility and fertilizing ability of frozen-thawed sperm of grass carp (Ctenopharyngodon idella) under hatchery conditions. Semen was collected by abdominal stripping from adult males and diluted to a ratio of $1: 3$ in Kurokura I or Kurokura II extender containing $10 \%, 15 \%$, or $20 \%$ glycerol. Diluted semen was packaged in $0.5-\mathrm{ml}$ straws and left to equilibrate for 30 $\min$ at $4^{\circ} \mathrm{C}$. Following equilibration, the straws were exposed to liquid nitrogen vapor for $10 \mathrm{~min}$ and plunged into liquid nitrogen $\left(-196^{\circ} \mathrm{C}\right)$. Straws were thawed in a water bath at $30^{\circ} \mathrm{C}$ for $10 \mathrm{~s}$ to determine the post-thaw motility and movement duration. The spermatozoa:egg ratio in fertilization experiments was $1 \times 10^{5}: 1$. The highest mean fertilization rate $(95.63 \pm 0.52$; $p>0.05$ ) was obtained with semen frozen in Kurokura I extender containing $10 \%$ glycerol. Results indicate that grass carp sperm can be successfully cryopreserved with ionic extenders containing glycerol at $10-20 \%$.
\end{abstract}

\footnotetext{
* Corresponding author. E-mail address: yfbozkurt@yahoo.com
} 


\section{Introduction}

Grass carp (Ctenopharyngodon idella) is one of the most important farmed freshwater fish species with an annual global production of 3,775,267 tons in the year 2008 (FAO, 2008). Because of its herbivorous feeding habits, grass carp enjoys considerable appreciation as a biological control of nuisance aquatic vegetation.

Cryopreservation is a specific and economic tool for conserving genetic resources. Successful cryopreservation of fish spermatozoa allows for an increased number of offspring from genetically superior males, more efficient transport of semen, and a yearround supply of male gametes. Cryopreservation increases the economic utilization of males and is necessary to establish gene banks (Munkittrick and Moccia, 1984).

The multiplicity of cryopreservation procedures affects the consistency of fertilization results. Differences in diluents, cryoprotectants, and freezing techniques make it difficult to compare procedures (Lubzens et al., 1997). However, different methods of fish sperm cryopreservation reveal common problems such as considerable variability in spermatozoa motility and a wide range of survival and fertility in spermatozoa after thawing (Tekin et al., 2007). While differences in diluents, cryoprotectants, and freezing techniques cause wide variation in fertilization results, the most reliable indicator of successful semen cryopreservation is the fertilization rate.

Generally, two types of extenders are used for cryopreservation of fish spermatozoa: seminal plasma-mimicking media and simple carbohydrate-based solutions (Linhart et al., 2000; Akçay et al., 2004). Dimethyl sulphoxide (DMSO) is usually used as an internal cryoprotective agent, but other cryoprotectants such as dimethyl acetamide (DMA), ethylene glycol, and glycerol also produce efficient results (Lahnsteiner et al., 1995). The use of an appropriate cryoprotectant prevents cellular disruption and membrane damage during freezing and thawing.

Methods of sperm cryopreservation have been reported in many fish species, especially large commercial species such as salmonids and marine teleosts (Suquet et al., 2000; Cabrita et al., 2001; Chao and Liao, 2001; Tekin et al., 2003) but also in grass carp (Withler, 1981; Chen et al., 1992). The availability of a reliable method for cryopreservation of grass carp sperm will increase reproduction efficiency in hatcheries. The purpose of this study was to investigate the effect of ionic extenders containing different ratios of glycerol on post-thaw motility and fertilizing ability of frozen grass carp spermatozoa under hatchery conditions.

\section{Materials and Methods}

Broodstock management. Experiments were carried out at the State Hydraulic Works (SHW) Fish Production Station in Adana, Turkey. Broodstock were held in earthen ponds under a natural photoperiod regime. The water temperature varied $23-25^{\circ} \mathrm{C}$ during the spawning season. Broodstock were collected from the wintering ponds by seining and transported to the hatchery $48 \mathrm{~h}$ prior to gamete collection. In the hatchery, male and female broodfish were held separately in shaded 1000-I tanks supplied with continuously $(2.5 \mathrm{l} / \mathrm{min})$ well-aerated water of $24^{\circ} \mathrm{C}$. Fish were not fed during the experiment.

Gamete collection. Spermiation and ovulation were induced with an intraperitoneally injected GnRH analogue, Ovopel, which is obtainable as pellets weighing approximately $25 \mathrm{mg}$ (Horvath et al., 1997). Each pellet contains 18-20 $\mathrm{gg}$ [D-Ala6, Pro9] NEt-mGnRH and $8-10 \mathrm{mg}$ dopamine D2 receptor antagonist (metoclopramide). Males and females were injected with the same dose: $1 \mathrm{U} / \mathrm{kg}$ body weight suspended in $0.65 \% \mathrm{NaCl}$ solution. Males received a single dose $24 \mathrm{~h}$ before stripping while females received a priming dose (10\% of the total) $24 \mathrm{~h}$ before stripping and a resolving dose (the remaining 90\%) $12 \mathrm{~h}$ later. Before stripping, broodfish were anesthetized in a $5 \mathrm{ppm}$ solution of Quinaldine (Reanal Ltd., Budapest, Hungary), removed from the water, and their genital apertures were wiped dry. Sperm was stripped from 15 males (3-5 years old; $1050.5 \pm 64.2 \mathrm{~g} ; 41.8 \pm 2.8 \mathrm{~cm}$ total length) by abdominal massage, directly into $20-$ $\mathrm{ml}$ calibrated glass beakers. Care was taken to avoid contamination with urine, mucus, feces, or water. Sperm samples were not pooled and the beakers were covered with parafilm and stored on ice in aerobic conditions. Eggs were collected from five females 
(4-5 years old; $1542.5 \pm 97.2 \mathrm{~g} ; 45.9 \pm 1.7 \mathrm{~cm}$ total length), stripped by gentle abdominal massage, and stored in aerobic conditions at room temperature. Eggs used in the fertilization experiments were well rounded and transparent. Eggs were used within $1 \mathrm{~h}$ after collection.

Semen evaluation. Spermatozoa were activated on a microscope slide by adding $1 \mu \mathrm{l}$ of semen to $50 \mu \mathrm{l}$ of activation solution ( $10 \mathrm{mM}$ Tris, $20 \mathrm{mM} \mathrm{NaCl}, 2 \mathrm{mM} \mathrm{CaCl}, \mathrm{pH} 8.5$; Jahnichen et al., 1999). Motility was observed using a dark field microscope at $200 \times$ magnification on a cold table $\left(4^{\circ} \mathrm{C}\right)$ and expressed as the percentage of cells with progressive motility. Duration of sperm motility was determined using a chronometer (sensitivity $1 / 100 \mathrm{~s}$ ) from the time that the activation solution was added to the sperm samples. Spermatozoa density was determined using a $100-\mu \mathrm{m}$ deep Thoma hemocytometer (TH-100, Hecht-Assistent, Sondheim, Germany) at 200× magnification with an Olympus B X50 phase contrast microscope (Olympus, Japan) and expressed as spermatozoa $\times 10^{9} / \mathrm{ml}$ (three replicates). Sperm pH was measured using indicator papers (Merck 5.5-9) before counting. To validate motility measurements, preliminary tests were carried out using three samples. For cryopreservation experiments, samples below $80 \%$ motile spermatozoa were discarded.

Extenders and dilution. Collected semen from the 15 males was pooled into equal aliquots according to the required semen volume and sperm density needed to eliminate effects of individual variability of the donors. Semen and extenders were kept at $4{ }^{\circ} \mathrm{C}$, then diluted at a ratio of $1: 3$ (semen/extender) with an extender plus glycerol at $10 \%$, $15 \%$, or $20 \%$. Two extenders were used: Kurokura I, containing $750 \mathrm{Mm} \mathrm{NaCl}, 20 \mathrm{mM}$ $\mathrm{KCl}, 20 \mathrm{mM} \mathrm{CaCl}$, and $20 \mathrm{mM} \mathrm{NaHCO}$, and Kurokura II, containing $440 \mathrm{mM} \mathrm{NaCl}, 620$ $\mathrm{mM} \mathrm{KCl}, 22 \mathrm{mM} \mathrm{CaCl} 2,8 \mathrm{mM} \mathrm{MgCl}$, and $20 \mathrm{mM} \mathrm{NaHCO}_{3}$ (Kurokura et al., 1984).

Freezing and thawing. Within $1 \mathrm{~h}$ after sperm collection, diluted semen samples were drawn into $0.5 \mathrm{ml}$ plastic straws (IMV, France) and sealed with polyvinyl alcohol (PVA). Having been diluted, the semen samples were equilibrated for $30 \mathrm{~min}$ at $4^{\circ} \mathrm{C}$. Following equilibration, the straws were placed on a styrofoam rack that floated on the surface of liquid nitrogen in a styrofoam box. The straws were frozen in the liquid nitrogen vapor 3 $\mathrm{cm}$ above the surface of the liquid nitrogen (about $-140^{\circ} \mathrm{C}$ ) for $10 \mathrm{~min}$, then plunged into the liquid nitrogen $\left(-196^{\circ} \mathrm{C}\right)$ and stored for several days. Frozen straws were thawed by plunging them into a water bath at $30^{\circ} \mathrm{C}$ for $10 \mathrm{~s}$. Thawed sperm was activated using $0.3 \% \mathrm{NaCl}$ and observed under a microscope to determine sperm motility and motility duration.

Fertilization experiments. Pooled eggs from three females were used to determine fertilization rates. Egg samples ( $2 \mathrm{~g} ; 100-200$ eggs) were inseminated in dry Petri dishes with fresh sperm or frozen sperm immediately after thawing at a spermatozoa:egg ratio of $1 \times 10^{5}: 1$. Eggs were inseminated by the dry fertilization technique using a solution of $3 \mathrm{~g}$ urea and $4 \mathrm{~g} \mathrm{NaCl}$ in 1 I distilled water. The sperm and eggs were slightly stirred for $30 \mathrm{~min}$, washed with hatchery water $\left(24^{\circ} \mathrm{C} ; 9 \mathrm{mg} / \mathrm{l} \mathrm{O} \mathrm{O}_{2}\right.$ ), and gently transferred to labeled Zuger glass incubators with running water $\left(24^{\circ} \mathrm{C}\right)$ where they were kept until hatching (3-4 d). Living and dead eggs were counted in each incubator during incubation and dead eggs were removed. When the fertilized eggs developed to embryos at the gastrula stage, the fertilization rate (number of gastrula stage embryos/number of total eggs) was calculated.

Statistical analysis. Results are presented as means \pm SE. Differences between parameters were analyzed by repeated analysis of variance (ANOVA). Significant means were subjected to a multiple comparison test (Duncan) for post-hoc comparisons at a level of $a=0.05$. Analyses were carried out using SPSS 10 for Windows Statistical Software Package.

\section{Results}

The mean semen volume, spermatozoa motility, movement duration, spermatozoa density, and $\mathrm{pH}$ of the fifteen fresh milt samples were $7.2 \pm 0.4 \mathrm{ml}, 85.7 \pm 1.15 \%$, $64.2 \pm 0.36 \mathrm{~s}, 12.4 \times 10^{9} / \mathrm{ml}$, and 7.3 , respectively. The best fertility was obtained with Extender I and $10 \%$ glycerol although fertilization rates did not significantly differ 
( $p>0.05)$ between treatments (Table 1$)$. The overall fertilization rate of the frozen-

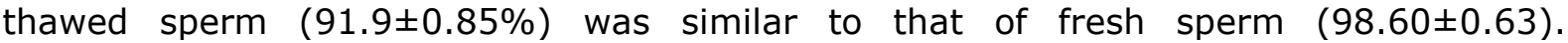
Interaction between the extenders and cryoprotectants was not significant with regard to fertilization rates $(F=1.012, p>0.05)$.

Table 1. Fertilization rate and motility duration using cryopreserved Ctenopharyngodon idella spermatozoa with the addition of glycerol as a cryoprotectant.

\begin{tabular}{|c|c|c|c|c|c|c|}
\hline \multirow[b]{2}{*}{$\begin{array}{l}\text { Kurokura } \\
\text { extender }\end{array}$} & \multirow[b]{2}{*}{$\begin{array}{c}\text { Glycerol } \\
(\%)\end{array}$} & \multicolumn{4}{|c|}{ Fertilization rate (\%) } & \multirow{2}{*}{$\begin{array}{c}\text { Motility } \\
\text { duration } \\
\text { (s) }\end{array}$} \\
\hline & & Trial 1 & Trial 2 & Trial 3 & Mean $\pm S E$ & \\
\hline I & 10 & 96.1 & 95.1 & 93.6 & $95.63 \pm 0.52$ & $37^{a}$ \\
\hline II & 10 & 95.2 & 90.8 & 93.2 & $93.26 \pm 1.27$ & $28^{\mathrm{a}}$ \\
\hline I & 15 & 85.6 & 90.7 & 85.3 & 1.75 & $20^{\mathrm{b}}$ \\
\hline II & 15 & 85.7 & 90.6 & 95.3 & $90.53 \pm 2.77$ & $23^{a b}$ \\
\hline I & 20 & 90.5 & 90.2 & 95.6 & $92.10 \pm 1.75$ & $25^{\mathrm{ab}}$ \\
\hline II & 20 & 90.3 & 95.2 & 95.5 & $93.67 \pm 1.68$ & $20^{b}$ \\
\hline Fresh seme & en - & 99.7 & 97.5 & 98.6 & $98.60 \pm 0.63$ & $84^{c}$ \\
\hline
\end{tabular}

Mean values in a column with different superscripts significantly differ $(p<0.05)$.

Motility was high (over 70\%) in the diluted sperm before freezing and following cryopreservation. Motility was not significantly lower in frozen-thawed sperm than in fresh sperm. The drops in motility before and after freezing were statistically similar for both extenders (70-85\%). Semen frozen with Extender I and $10 \%$ glycerol had the highest post-thaw motility $(85 \%)$, but this parameter did not significantly differ $(p>0.05)$ from other treatments. The interactions between extenders and cryoprotectant ratios did not significantly

differ with regard to post-thaw motility $(F=2.250, p>0.05)$.

A significant decrease in motility duration occurred following cryopreservation. Differences between mean motility durations were significant $(p<0.05)$ when cryoprotectant ratios were taken into consideration. The overall motility duration of thawed spermatozoa was $28.16 \pm 1.83 \mathrm{~s}$. Interactions between the extenders and cryoprotectant ratios were significant with regard to post-thaw motility duration $(F=$ 296.48, $p<0.05)$.

\section{Discussion}

Selecting a suitable extender is a key factor in successful cryopreservation of fish semen. Extenders that do not initiate motility result in better post-thaw motility (Billard, 1992). Saline, glucose, ionic, or seminal plasma-mimicking media are particularly popular for the cryopreservation of carp sperm (Koldras and Bieniarz, 1990; Linhart et al., 2000). In the present study, two ion-based extenders (Kurokura I and II) used to cryopreserve fish sperm (Zhang et al., 2003; Chen, 2007) were tested as cryopreservants for grass carp sperm. Glycerol, one of the most commonly used internal permeable cryoprotectants, was added at $10-20 \%$. The extenders and cryoprotectant yielded comparatively high fertilization rates in the frozen semen. The high fertilization results can be linked to adequate penetration of the glycerol into cell membranes.

The concentration of post-thaw sperm needed for optimal fertilization is approximately 100 times higher than that of fresh semen (Lubzens et al., 1997). Postthaw fertilization rates obtained with sperm to egg ratios of 1.3-2.6 $\times 10^{6}: 1$ did not reach that of fresh sperm in cyprinids (Lahnsteiner et al., 2003). Results are similar in turbot (Suquet et al., 1998) and flounder (Zhang et al., 2003). However, using our protocol with a 1:100,000 egg:spermatozoa ratio, almost the same fertilization efficiency was obtained whether frozen or fresh semen was used. This may be due to differences in extender, cryoprotectant, equilibration, egg quality, or protocol. In the present study, the interaction between the percentage of motile post-thaw sperm and fertilizing capacity was highly positive, similar to results in common carp (Linhart et al., 2000), African catfish (Rurangwa et al., 2001) and turbot (Dreanno et al., 1999).

Dilution of cryoprotectants can cause a significant increase in fragility in spermatozoa exposed to hypo-osmotic shock (Cabrita et al., 2001). In the present study, no significant differences in fertilization rates were observed between extenders, indicating that glycerol has a protective effect against damage to membranes caused by freezing. Some authors recommend allowing time to equilibrate after dilution so that cryoprotectants can penetrate the spermatozoa before cryopreservation (Lahnsteiner et 
al., 1996) but equilibration did not improve cryopreservation success in Cyprinus carpio (Lubzens et al., 1997; Linhart et al., 2000). In the present study, diluted samples were equilibrated for $30 \mathrm{~min}$ at $4^{\circ} \mathrm{C}$.

Motility is an important characteristic for estimating the quality of fresh as well as cryopreserved sperm (Lahnsteiner et al., 1996). In the current study, the freezing and thawing process did not significantly influence the percent of motile sperm but it significantly reduced the motility duration. Similar motility parameters have been reported for frozen-thawed spermatozoa (Kurokura et al., 1984; Lahnsteiner et al., 1996; Lubzens et al., 1997) but post-thaw motility was significantly lower in cryopreserved turbot sperm than in fresh (Dreanno et al., 1999).

In conclusion, our study corroborates previous reports on species-specific requirements for cryoprotectants and extenders in fish. The simplified extender composition, low level of dilution, and rapid holding time in our study resulted in less complicated freezing procedures. The cryopreservation protocol developed in this study is rather effective and grass carp sperm can be successfully cryopreserved with ionic extenders containing $10-20 \%$ glycerol. Further studies are needed to evaluate viability, survival, and development of larvae produced from cryopreserved grass carp sperm.

\section{Acknowledgements}

The authors are grateful to the staff of the State Hydraulic Works (SHW) Fish Production Station, Adana, Turkey.

\section{References}

Akçay E., Bozkurt Y., Seçer S., and N. Tekin, 2004. Cryopreservation of mirror carp semen. Turkish J. Vet. Anim. Sci., 28(5):837-843.

Billard R., 1992. Reproduction in rainbow trout. Aquaculture, 100:263-298.

Cabrita E., Anel L. and M.P. Hernaez, 2001. Effect of external CPAs as membrane stabilizers on cryopreserved rainbow trout spermatozoa. Theriogenology, 56:623-635.

Chao N.H. and I.C. Liao, 2001. Cryopreservation of finfish and shellfish gametes and embryos. Aquaculture, 197:161-189.

Chen S.L., 2007. Theory and Techniques of Fish Spermatozoa and Embryo Cryopreservation. China Agriculture Press, Beijing. pp. 47-298.

Chen S.L., Liu X.T., Lu D.C., Zhang L.Z., Fu C.J. and J.P. Fang, 1992. Cryopreservation of spermatozoa of silver carp, common carp, blunt snout bream and grass carp. Acta Zool. Sinica, 38:413-424.

Dreanno C., Cosson J., Suquet M., Seguin F., Dorange G. and R. Billard, 1999. Nucleotides content, oxidative phosphorylation, morphology and fertilizing capacity of turbot (Psetta maxima) spermatozoa during the motility period. Mol. Reprod. Dev., 53: 230-243.

FAO, 2008. FAO Yearbook of Fishery Statistics Summary Tables. ftp://ftp.fao.org/fi/STAT/summary/a-6.pdf.

Horvath L., Szabó T. and J. Burke, 1997. Hatchery testing of GnRH analoguecontaining pellets on ovulation in four cyprinid species. Polish Arch. Hydrobiol., 44:221226.

Jahnichen H., Warnecke W., Trölsch E., KohImann K., Bergler H. and H.J. Pluta, 1999. Motility and fertilizing capability of cryopreserved Acipenser ruthenus L. sperm. J. Appl. Ichthyol., 15:204-206.

Koldras M. and K. Bieniarz, 1990. Cryopreservation of carp sperm. Pol. Arch. Hydrobiol., 34:125-134.

Kurokura H., Hirano R., Tomita M. and M. Iwahashi, 1984. Cryopreservation of carp sperm. Aquaculture, 37:267-273.

Lahnsteiner F., Weismann T. and R.A. Patzner, 1995. A uniform method for cryopreservation of semen of salmonid fish (Oncorhynchus mykiss, Salmo trutta fario, Salmo trutta lacustris, Coregonus sp.). Aquacult. Res., 26:801-807. 
Lahnsteiner F., Berger B., Weismann T. and R.A. Patzner, 1996. Motility of spermatozoa of Alburnus alburnus (Cyprinidae) and its relationship to seminal plasma composition and sperm metabolism. Fish Physiol. Biochem., 15:167-179.

Lahnsteiner F., Berger B. and T. Weismann, 2003. Effects of media, fertilization technique, extender, straw volume, and sperm to egg ratio on hatchability of cyprinid embryos, using cryopreserved semen. Theriogenology, 60(5):829-841.

Linhart O., Rodina M. and J. Cosson, 2000. Cryopreservation of sperm in common carp: sperm motility and hatching success of embryos. Cryobiology, 41:241-250.

Lubzens E., Daube N., Pekarsky I., Magnus Y., Cohen A., Yusefovich F. and P. Feigin, 1997. Carp (Cyprinus carpio L.) spermatozoa cryobanks-strategies in research and application. Aquaculture, 155:13-30.

Munkittrick K.R. and R.D. Moccia, 1984. Advances in the cryopreservation of salmonid semen and suitability for a production-scale artificial fertilization program. Theriogenology, 21:645-659.

Rurangwa E., Volckaert F.A.M., Huyskens G., Kime D.E. and F. Ollevier, 2001. Quality control of refrigerated and cryopreserved semen using computer-assisted sperm analysis (CASA), viable staining and standardized fertilisation in African catfish (Clarias gariepinus). Theriogenology, 55:751-769.

Suquet M., Dréanno C., Petton B., Norman Y., Omnes M.H. and R. Billard, 1998. Long-term effect of the cryopreservation of turbot (Psetta maxima) spermatozoa. Aquat. Living Resour., 11:45-48.

Suquet M., Dreanno C., Fauvel C., Cosson I. and R. Billard, 2000. Cryopreservation of sperm in marine fish. Aquacult. Res., 31:231-243.

Tekin N., Seçer S., Akcay E. and Y. Bozkurt, 2003. Cryopreservation of rainbow trout (Oncorhynchus mykiss) semen. Isr. J. Aquacult. - Bamidgeh, 55(3):208-212.

http://www.siamb.org.il/uploads/55 3 tekin abs.pdf

Tekin N., Seçer S., Akçay E., Bozkurt Y. and S. Kayam, 2007. Effects of glycerol additions on post-thaw fertility of frozen rainbow trout sperm, with an emphasis on interaction between extender and cryoprotectant. J. Appl. Ichthyol., 23(1):60-63.

Withler F.C., 1981. Cryopreservation of spermatozoa of some freshwater fishes cultured in South and Southeast Asia. Aquaculture, 26:395-398.

Zhang Y.Z., Zhang S.C., Liu X.Z., Xu Y.Y., Wang C.L., Sawant M.S., Li J. and S.L. Chen, 2003. Cryopreservation of flounder (Paralichthys olivaceus) sperm with a practical methodology. Theriogenology, 60:989-996. 